\title{
Genética da Resistência de Cultivares de Arroz à Raça IA-1 de Pyricularia grisea
}

\author{
Cley D.M. Nunes ${ }^{1}$, Fernando I. F. Carvalho ${ }^{2}$, Carlos R. Pierobom ${ }^{3}$ \& Antônio C. Oliveira ${ }^{2}$ \\ 1Embrapa Clima Temperado, Cx. Postal 403, CEP 96001-970, Pelotas, RS, e-mail: cley@cpact.embrapa.br; \\ ${ }^{2}$ Departamento de Fitotecnia; ${ }^{3}$ Departamento de Fitossanidade, Faculdade de Agronomia Eliseu Maciel, \\ Universidade Federal de Pelotas, Cx. Postal 353, CEP 96010-900, Pelotas, RS
}

Autor para correspondência: Cley D. Martins Nunes

NUNES, C.D.M., CARVALHO, F.I.F., PIEROBOM, C.R., OLIVEIRA \& A.C. Resistência genética de cultivares de arroz irrigado à raça IA-1 abd de Pyricularia grisea. Fitopatologia Brasileira 32:064-069. 2007.

\section{RESUMO}

A brusone é a principal doença da cultura do arroz irrigado e pode comprometer até $100 \%$ da produção de grãos de algumas lavouras isoladas nos casos de ataques epidêmicos. A melhor forma para o controle desta doença é o emprego da resistência genética, por ser mais econômica. O trabalho teve por objetivo avaliar a herdabilidade, número de genes e ação gênica na herança do caráter da resistência à raça IA-1abd de Pyricularia grisea de genótipos de arroz. A inoculação do fungo foi realizada sobre as populações fixas $\left(\mathrm{P}_{1}, \mathrm{P}_{2}\right.$, e $\left.\mathrm{F}_{1}\right)$ e segregantes $\left(\mathrm{F}_{2}, \mathrm{RC}_{1} \mathrm{~F}_{1}\right.$ e $\left.\mathrm{RC}_{2} \mathrm{~F}_{1}\right)$ obtidas entre as cultivares BRS Atalanta, Fanny (suscetíveis), BRS 7 "Taim" e BRS Firmeza (resistentes). Os resultados evidenciaram dominância da ação gênica com base nas seis gerações $\left(\mathrm{P}_{1}, \mathrm{P}_{2}, \mathrm{~F}_{1}, \mathrm{~F}_{2}, \mathrm{RC}_{1} \mathrm{~F}_{1}\right.$ e $\left.\mathrm{RC}_{2} \mathrm{~F}_{1}\right)$, o que confirma a presença de um gene com dois alelos. Nos cruzamentos recíprocos entre os genótipos observou-se que não houve presença do efeito materno. No cruzamento entre parentais resistentes à brusone (BRS 7 "Taim” e BRS Firmeza) não houve segregação nas gerações $\mathrm{F}_{2}$ e retrocruzamentos, sugerindo que ambos os genitores tem a mesma constituição genética para reação de resistência à raça IA-1abd. As gerações segregantes $\left(\mathrm{F}_{2}\right.$ e $\left.\mathrm{RC}_{1} \mathrm{~F}_{1}\right)$ de todos os cruzamentos entre genótipos resistentes e suscetíveis apresentaram probabilidades significativas para freqüência esperada de 3:1 e 1:1, respectivamente, o que sugere que estas cultivares, "Taim" e BRS Firmeza, possuem um gene dominante responsável pela expressão do caracter da reação de resistência.

Palavras-chave adicionais: Oryza sativa, brusone, melhoramento de plantas.

\begin{abstract}
Genetics of resistance in rice cultivar to race $1 \mathrm{~A}$ of Pyricularia grisea

Rice blast poses the greatest disease threat to irrigated rice, causing losses up to $100 \%$ in grain yield under epidemic attack. Genetic resistance is the most effective and environmentally sound way to control the disease. Thus, the objective of this work was to evaluate the number of genes and gene action involved in the inheritance of resistance to race IA-1abd of Pyricularia grisea in rice genotypes. The inoculation of the fungus was performed on fixed ( $\mathrm{P}_{1}$, $\mathrm{P}_{2}$ and $\left.\mathrm{F}_{1}\right)$ and segregating $\left(\mathrm{F}_{2}, \mathrm{RC}_{1} \mathrm{~F}_{1}\right.$ and $\left.\mathrm{RC}_{2} \mathrm{~F}_{1}\right)$ populations, composed of cultivars BRS 7 "Taim", BRS Firmeza, BRS Atalanta and Fanny. The results show that there is dominance for the gene action based on the six generations $\left(\mathrm{P}_{1}, \mathrm{P}_{2}, \mathrm{~F}_{1}, \mathrm{~F}_{2}, \mathrm{RC}_{1} \mathrm{~F}_{1}\right.$ and $\left.\mathrm{RC}_{2} \mathrm{~F}_{1}\right)$, which confirms the presence of one gene with two alleles. In all reciprocal crosses no maternal effect was observed. In the cross between resistant parents (BRS 7 "Taim" and BRS Firmeza), there was no segregation in the generations $\mathrm{F}_{2}$ and backcrosses, suggesting that both parents have the same genetic constitution for the reaction of resistance to the IA-1 abd race. The segregating generations ( $\mathrm{F} 2$ and $\mathrm{RC}_{1} \mathrm{~F}_{1}$ ) of all crosses between resistant and susceptible genotypes did not differ from the expected ratio of $3: 1$ and 1:1, respectively, suggesting that these cultivars, "Taim" and BRS Firmeza, have one dominant gene responsible for the expression of the character resistance reaction.
\end{abstract}

Additional keywords: Oryza sativa, rice blast, plant breeding.

No cultivo de arroz irrigado, a brusone é uma das doenças fúngicas mais importantes pela sua ampla distribuição geográfica e capacidade de destruição das cultivares suscetíveis sob condições ambientais

* Parte da tese de doutorado do primeiro autor. Universidade Federal de Pelotas. 2005. favoráveis. Nas últimas décadas, muitas informações foram obtidas sobre a genética da reação de resistência da plantas de arroz. A herança da resistência à brusone pode ser conferida por um a três pares de genes independentes sendo que a resistência é dominante na maioria dos casos (McCouch et al., 1994).

No Japão, foram identificados 14 alelos (Pi-k, Pi$k^{s}$, Pi-k ${ }^{p}, P i-k^{h}$, Pi-k ${ }^{m}, P i-t a, P i-t^{2}$, Pi-z e Pi-zt, Pi-i, Pi-a, 
Pi-b, Pi-m, Pi-t) localizados em oito loci. Entre eles, cinco alelos (Pi-k, Pi-k $\left.\mathrm{k}^{\mathrm{s}}, \mathrm{Pi}-\mathrm{k}^{\mathrm{m}}, \mathrm{Pi}-\mathrm{k}^{\mathrm{p}}, \mathrm{Pi}-\mathrm{k}^{\mathrm{h}}\right)$ estão localizados no locus Pi-k, dois (Pi-ta, Pi-ta ${ }^{2}$ ) no locus Pi-ta e dois (Pi-z e $\mathrm{Pi}-\mathrm{z}^{\mathrm{t}}$ ) no locus Pi-z. Todos os alelos citados conferem, em separado, uma resistência vertical (McCouch et al., 1994).

Os genes de resistência a $P$. grisea presentes no germoplasma do programa de melhoramento genético de arroz irrigado no Brasil apresentam a seguinte distribuição: o gene Pi-b esta presente nas cultivares BR-IRGA 409, BR-IRGA 410, EMPASC 101, 102, 103, IAC 899, IR 22, IR 24, IR 841 e IR 6441; as cultivares IRGA 408, IR 9202 e P 805-84-4-1T possuem o gene $\mathrm{Pi}-\mathrm{ta}$; e as cultivares Lebonnet e Dawn o gene Pi-k (Tanaka, 1983). As cultivares que possuem os genes Pi-ta (IR-36 e El Paso 144) e Pi-ta ${ }^{2}$ (Katy, Drew e Tetep) são resistente aos principais patótipos de $P$. grisea dos EUA, IB-49 e IC-17 (Jia et al., 2004). A resistência das cultivares manifestada pelo gene $\mathrm{Pi}^{-\mathrm{ta}^{2}}$ tem maior espectro da resistência comparado com gene Pi-ta, por conter outras proteínas além das codificadas pela resistência de $\mathrm{Pi}$-ta. A diferença relativa da expressão da resistência em ambas cultivares resistente $\left(\mathrm{Pi}-\mathrm{ta}^{+}\right)$ e suscetível (Pi-ta') está no compartilhamento de uma única diferença de aminoácido, relativo à proteína de resistência Pi-ta: serina em vez de alanina, na posição 918 (Bryan et al., 2000).

O genótipo Te-tep foi altamente resistente em diferentes regiões produtoras de arroz do mundo. No seu genoma foram registrados os genes Pi-4a(t) e Pi-4b(t). O outro gene recentemente encontrado e transferido para linhagens isogênicas da cultivar CO39 foi Pi-tp(t). O marcador molecular RM 246 da analise de "Simple Sequence Lenght Polymorphism" (SSLP) utilizado na população F2 com segregação de 3R:1S (resistente/suscetível) foi mapeado no cromossomo 1 na distância de 8,0 cM (Barman et al., 2004).

A resistência à brusone na cultivar chinesa, Q14, é governada pelo gene de resistência Pi27(t), localizado no cromossomo 1. Na análise da população segregante $F_{2}$ na proporção de 3R:1S (resistente/ suscetível), os marcadores de microsatélite RM151 e RM259 foram encontrados ligados ao gene de resistência com freqüência de recombinação de 11,9 $\pm 2,8 \%$ e $9,7 \pm 8,0 \%$, respectivamente (Zhu et al., 2004).

Os trabalhos de herança genética entre Fukunishiki (Pi-Z) e C101A51 (Pi-2(t)) inoculado com a raça IK81-3 mostraram que a população $F_{2}$ foi resistente. Este resultado sugere que $\mathrm{Pi}-\mathrm{z}$ pode ser alélico ao Pi-2 (Inukai et al., 2005). Esta informação é confirmada por Kinoshita et al. (2003), revelando ainda que $\mathrm{Pi}-4 \mathrm{a}(\mathrm{t})$ foi identificado como sendo Pi-ta. O estudo da região genômica das linhagens que contém o gene Pi3(t) usando os marcadores moleculares de Pi5(t), mostrou que os genes são idênticos, ou seja,
Pi3(t) e Pi5(t) são os mesmos genes de resistência (Jeon et al., 2003).

Os testes de alelismo mostram que os genes das cultivares da série isolineas de CO $39(\mathrm{Pi}-1(\mathrm{t}), \mathrm{Pi}-$ 2(t), Pi-3(t), Pi-4a(t) e Pi-4b(t) ) são alélicos ou estão fortemente ligados aos genes da série Kiyosawa (Pik, Pi-z, Pi-i, Pi-ta e Pi-?), respectivamente (Inukai et al., 1994).

A herança da resistência à brusone foi estudada nos cruzamentos com Carreon, Zenith, CNM 4140, Dular, Te-tep e Tadukan (resistente) com CO 39 (suscetível) com isolado DRR (Directorate of Rice Research). Em todos os cruzamentos, as plantas $F_{1}$ mostraram-se resistentes e na geração $\mathrm{F}_{2}$ segregaram na proporção de 3 resistentes para 1 suscetível, revelando ser um caráter monogênico de ação dominante. No teste de alelismo, as populações $F_{2}$ dos cruzamentos Carreon x Dular; Carreon x Te-tep e Dular x Te-tep não segregaram para suscetibilidade, indicando simples gene de resistência (Pi-k) enquanto Carreon, Dular e Te-tep cruzado com Zenith, CNM 4140 e Tadukan segregaram na razão 15R:1S indicando que o gene presente em Dular, Te-tep e Carreon é diferente de Zenith, CNM 4140 e Tadukan (Padmavathi et al., 2005).

Nas espécies de arroz, estima-se que no mínimo 40 genes conferem resistência à brusone, mas destes somente 2 foram clonados (Pi-b e Pi-ta) (Babujee \& Gnanamanickam, 2000; Jia et al., 2004).

Alguns genes maiores de resistência à brusone foram identificados em linhagens endogâmicas recombinantes (RILs). Várias linhagens isogênicas (NILs) com genes diferentes foram estabelecidas no "International Rice Research Institute" (IRRI). Nestas estão incluídas IR49830-7-1-2-2 NILs (arroz irrigado), LTH NILs (retrocruzamento japonica) e CO39 NILs (retrocruzamento indica). Estas NILs podem ser usadas para avaliação da performance individual dos genes de resistência e a caracterização da população do patógeno e também para mapeamento de clones e piramidização de genes (Babujee \& Gnanamanickam, 2000).

O conhecimento das bases genéticas da reação de resistência à brusone das cultivares de arroz como: herdabilidade, número de genes e do tipo de ação gênica é de alta importância para a seleção de genótipos resistentes. A identificação do número e da combinação desses genes está intimamente relacionada com a patogenicidade na população de $P$. grisea obtida pela adaptação do fungo as novas cultivares, resultado da perda de resistência. Além disso, o conhecimento da ação gênica da reação de resistência à brusone proporciona planejamento rigoroso na escolha do germoplasma de trabalho, critérios para seleção de novos indivíduos, estabelecendo rotatividade dos genes de resistência 
para contornar os prováveis erros de estratégia no controle da doença. Assim, este trabalho visou avaliar alguns destes mecanismos genéticos para o caráter da resistência à brusone.

Para estudar a genética da resistência das cultivares de arroz à brusone foram feitos cruzamentos entre quatro cultivares, BRS 7 “Taim”, BRS Firmeza (resistentes), BRS Atalanta e Fanny (suscetíveis). Para a obtenção das populações fixas $\left(F_{1}\right)$ foram realizados cruzamentos no período de outubro/2003 a março de 2004, e para as populações segregantes $\left(\mathrm{F}_{2}, \mathrm{RC}_{1} \mathrm{~F}_{1}\right.$ e $\left.\mathrm{RC}_{2} \mathrm{~F}_{1}\right)$ no período de outubro de 2004 a março de 2005. Para detectar a possibilidade da existência de efeito materno foram realizados cruzamentos recíprocos, ou seja dar a condição de mãe ou de pai para cada cultivar.

As sementes de todas as gerações $\left(\mathrm{P}_{1}, \mathrm{P}_{2}, \mathrm{~F}_{1}\right.$, $\mathrm{F}_{2}, \mathrm{RC}_{1} \mathrm{~F}_{1}$ e $\mathrm{RC}_{2} \mathrm{~F}_{1}$ ) foram semeadas em conjunto na mesma bandeja $(30 \times 40 \times 4 \mathrm{~cm})$ no mês de setembro/2005 para os testes de reação de resistência à brusone. A densidade de sementes usada foi de 20 por cento maior que o número de plantas necessárias para o estudo (50 plantas para as gerações fixas $\mathrm{P}_{1}$, $\mathrm{P}_{2}, \mathrm{RC}_{1} \mathrm{~F}_{1}$ e $\mathrm{RC}_{2} \mathrm{~F}_{1}$ e 150 plantas para $\mathrm{F}_{2}$ ).

Quando as plantas atingiram os estádios de 2-3 folhas, foram adubadas em cobertura com $0,5 \mathrm{~g} . \mathrm{m}^{-}$ 2 de nitrogênio na forma de uréia, para aumentar a suscetibilidade à brusone.

O isolado de $P$. oryzae usado para o estudo foi obtido da seleção de isolados das cultivares de arroz, previamente identificado como IA-1abd, como mais agressiva às cultivares suscetíveis, Fanny e BRS Atalanta e com reação de resistência às cultivares BRS 7 "Taim" e BRS Firmeza. Para a produção de inóculo, o fungo foi cultivado meio de cultura de aveia e incubado durante 12 a 15 dias, sob luz fluorescente ( 12 horas iluminado/12 horas no escuro), à temperatura de $25^{\circ} \mathrm{C}$.

Quando as plântulas de arroz atingiram o estádio de 3-5 folhas, foram inoculadas com uma suspensão de esporos na concentração de $4,5 \times 10^{-5}$ esporos $\mathrm{mL}^{-1}$, no volume de $60 \mathrm{~mL}$ de inóculo por bandeja e transferidas para câmara de incubação com temperatura de 20 a $28{ }^{\circ} \mathrm{C}$ e umidade relativa superior a $90 \%$, permanecendo nestas condições durante 10 dias.

As avaliações das reações de resistência à brusone nas folhas foram feitas após a incubação, utilizando uma escala visual de notas de 1 a 9 baseando-se no tipo de reação conforme proposto pelo Centro Internacional de Agricultura Tropical, CIAT (1975). Os tipos de reações variando de 1 a 3 foram considerados como resistentes ou incompatíveis e de 4 a 9 como suscetíveis ou compatíveis. As oito cultivares da série diferencial internacionais foram semeadas e avaliadas para confirmação da raça, conforme as tabelas apresentadas por Ling \& $\mathrm{Ou}$ (1969).

A distribuição de freqüências para os dados de reação de resistência, foi aplicada em cada geração de todos os cruzamentos com o propósito de estimar a média e a variância do caráter, assim como, verificar o ajuste das distribuições obtidas, através da aplicação do teste de chi-quadrado, $\chi^{2}$, (Steel \& Torrie, 1980).

As reações à brusone dos descendentes dos cruzamentos entre cultivares resistentes e suscetíveis possibilitou um melhor entendimento da genética da resistência à doença das cultivares BRS 7 "Taim e BRS Firmeza. Neste trabalho, a ação gênica da reação de resistência à brusone revelou que de acordo com a distribuição de freqüência com base nas seis gerações (paternais, $\mathrm{F}_{1}, \mathrm{~F}_{2}, \mathrm{RC}_{1} \mathrm{~F}_{1}$ e $\mathrm{RC}_{2} \mathrm{~F}_{1}$ ), houve dominância do caráter de resistência sobre de suscetibilidade (Tabela 1). A hipótese da constituição genética da reação de resistência pode ser expressa por um gene com dois alelos; portanto, há diferença genética entre os dois genitores. Na geração F1, o genitor suscetível não manifesta o seu fenótipo pela ausência da ação do alelo recessivo no heterozigoto enquanto que o caráter de resistência está presente, o que confirma a sua ação de dominância sobre a suscetibilidade.

Nos cruzamentos entre genitores resistentes e suscetíveis, como "Taim" e Fanny, observouse a variância da média das gerações $F_{2}$ e $\mathrm{RC}_{1} \mathrm{~F}_{1}$ - nos retrocruzamentos com pais suscetíveis superior aos pais evidenciando segregação para o lado dominante (Tabela 1). Isto é mais evidente nos retrocruzamentos com o pai resistente, $\mathrm{RC}_{2} \mathrm{~F}_{1}$, onde todos os descendentes possuem resistência à brusone.

No cruzamento entre pais resistentes à brusone (BRS 7 "Taim" e BRS Firmeza) evidencia a ausência de diferenças genéticas para o controle da doença, isto é, não houve segregação nas gerações $F_{2}$ e nos retrocruzamentos, sugerindo que ambos os genitores têm a mesma constituição genética para reação de resistência à raça de $P$. grisea, IA-1abd.

Nos dez cruzamentos entre genótipos resistentes e suscetíveis e entre os progenitores resistentes não ocorreram diferenças que indicassem a existência de efeito materno (Tabela 1).

A hipótese um gene dominante controlar a reação de resistência à raça $\mathrm{IA}-1 \mathrm{abd}$ foi confirmada através do teste de ajustamento do Chi-quadrado $\left(\chi^{2}\right)$ (Tabela 2). A grande maioria dos cruzamentos apresentou probabilidades significativas para freqüência esperada de $3: 1,1: 1$ em todas as gerações segregantes $F_{2}$ e retrocruzamentos com pais suscetíveis, respectivamente, permitindo aceitação da hipótese formulada. A única exceção foi observada 
TABELA 1 - Distribuição de freqüências, número de indivíduos $(\mathbf{N})$, médias $(\mathbf{X})$ e variâncias $\left(\sigma^{2}\right)$, em três gerações fixas $\left(\mathrm{P}_{1}, \mathrm{P}_{2}\right.$ e $\left.\mathrm{F}_{1}\right)$ e três gerações segregantes $\left(\mathrm{F}_{2}, \mathrm{RC}_{1} \mathrm{~F}_{1}\right.$ e $\left.\mathrm{RC}_{2} \mathrm{~F}_{1}\right)$, em diferentes cruzamentos, realizados entre quatro genótipos de arroz. FAEM/UFPel, Pelotas, 2005

\begin{tabular}{|c|c|c|c|c|c|c|c|c|c|c|c|c|}
\hline \multirow{2}{*}{$\begin{array}{l}\text { Cruzamentos e Gerações } \\
\text { Fanny X BRS } 7 \text { - Taim }\end{array}$} & \multicolumn{12}{|c|}{ Classes (Notas de 1 a 9) } \\
\hline & 1 & 2 & 3 & 4 & 5 & 6 & 7 & 8 & 9 & $\mathbf{N}$ & $\mathbf{X}$ & 2 \\
\hline $\mathrm{P} 1$ & & & & & & & 7 & 17 & 25 & 49 & 8,37 & 0,53 \\
\hline P2 & 23 & 25 & 5 & & & & & & & 53 & 1,67 & 0,42 \\
\hline $\mathrm{F} 1$ & 27 & 17 & 7 & & & & & & & 51 & 1,61 & 0,52 \\
\hline F2 & 89 & 30 & 6 & & & & 26 & 8 & 6 & 165 & 2,83 & 7,40 \\
\hline $\mathrm{RC} 1 \mathrm{~F} 1$ & & 17 & 4 & & & & & 3 & 21 & 45 & 5,76 & 11,51 \\
\hline $\mathrm{RC} 2 \mathrm{~F} 1$ & 29 & 17 & 3 & & & & & & & 49 & 1,47 & 0,38 \\
\hline BRS 7 - Taim X Fanny & 1 & 2 & 3 & 4 & 5 & 6 & 7 & 8 & 9 & $\mathbf{N}$ & $\mathbf{X}$ & 2 \\
\hline $\mathrm{P} 1$ & 32 & 14 & 6 & & & & & & & 52 & 1,50 & 0,49 \\
\hline P2 & & & & & & & & 20 & 36 & 56 & 8,64 & 0,23 \\
\hline $\mathrm{F} 1$ & 21 & 20 & 8 & & & & & & & 49 & 1,74 & 0,53 \\
\hline $\mathrm{F} 2$ & 51 & 48 & 18 & & & & 22 & 12 & 5 & 156 & 3,18 & 6,96 \\
\hline RC1F1 & 23 & 21 & 4 & & & & & & & 48 & 1,60 & 0,41 \\
\hline $\mathrm{RC} 2 \mathrm{~F} 1$ & & 20 & 5 & & & & 5 & & 19 & 49 & 5,33 & 10,25 \\
\hline BRS 7 - Taim X BRS Firmeza & 1 & 2 & 3 & 4 & 5 & 6 & 7 & 8 & 9 & $\mathbf{N}$ & $\mathbf{X}$ & 2 \\
\hline $\mathrm{P} 1$ & 31 & 18 & 6 & & & & & & & 55 & 1,55 & 0,47 \\
\hline $\mathrm{P} 2$ & 27 & 18 & & & & & & & & 45 & 1,40 & 0,25 \\
\hline $\mathrm{F} 1$ & 36 & 12 & 2 & & & & & & & 50 & 1,32 & 0,30 \\
\hline $\mathrm{F} 2$ & 84 & 48 & 12 & & & & & & & 144 & 1,50 & 0,42 \\
\hline $\mathrm{RC} 1 \mathrm{~F} 1$ & 25 & 10 & 8 & & & & & & & 43 & 1,60 & 0,63 \\
\hline $\mathrm{RC} 2 \mathrm{~F} 1$ & 19 & 24 & & & & & & & & 43 & 1,56 & 0,25 \\
\hline Fanny X BRS Firmeza & 1 & 2 & 3 & 4 & 5 & 6 & 7 & 8 & 9 & $\mathbf{N}$ & $\mathbf{X}$ & 2 \\
\hline $\mathrm{P} 1$ & & & & & & & 6 & 16 & 27 & 49 & 8,43 & 0,50 \\
\hline P2 & 28 & 19 & & & & & & & & 47 & 1,40 & 0,25 \\
\hline $\mathrm{F} 1$ & 15 & 30 & 18 & & & & & & & 63 & 2,05 & 0,53 \\
\hline $\mathrm{F} 2$ & 29 & 60 & 20 & & & & 10 & 16 & 10 & 145 & 3,43 & 7,43 \\
\hline $\mathrm{RC} 1 \mathrm{~F} 1$ & 4 & 19 & & & & & 9 & 7 & 7 & 46 & 4,87 & 9,89 \\
\hline $\mathrm{RC} 2 \mathrm{~F} 1$ & 20 & 19 & 5 & & & & & & & 44 & 1,66 & 0,46 \\
\hline BRS Atalanta $X \quad$ BRS 7 - Taim & 1 & 2 & 3 & 4 & 5 & 6 & 7 & 8 & 9 & $\mathbf{N}$ & $\mathbf{X}$ & 2 \\
\hline $\mathrm{P} 1$ & & & & & & 23 & 20 & 10 & & 53 & 6,75 & 0,57 \\
\hline $\mathrm{P} 2$ & 38 & 14 & 2 & & & & & & & 54 & 1,33 & 0,30 \\
\hline F1 & 20 & 7 & 5 & & & & & & & 32 & 1,53 & 0,58 \\
\hline $\mathrm{F} 2$ & 60 & 32 & 18 & & & 1 & 21 & 15 & & 147 & 3,07 & 6,79 \\
\hline $\mathrm{RC} 1 \mathrm{~F} 1$ & 3 & 12 & 6 & & & 2 & 13 & 5 & 2 & 43 & 4,79 & 7,36 \\
\hline $\mathrm{RC} 2 \mathrm{~F} 1$ & 27 & 16 & 4 & & & & & & & 47 & 1,51 & 0,43 \\
\hline BRS Atalanta X BRS Firmeza & 1 & 2 & 3 & 4 & 5 & 6 & 7 & 8 & 9 & $\mathbf{N}$ & $\mathbf{X}$ & 2 \\
\hline $\mathrm{P} 1$ & & & & & & 8 & 26 & 15 & & 49 & 7,14 & 0,46 \\
\hline P2 & 29 & 16 & & & & & & & & 45 & 1,36 & 0,23 \\
\hline F1 & 11 & 14 & 26 & & & & & & & 51 & 2,29 & 0,65 \\
\hline F2 & 18 & 42 & 34 & & & 8 & 13 & 10 & & 125 & 3,38 & 5,04 \\
\hline $\mathrm{RC} 1 \mathrm{~F} 1$ & 4 & 10 & 2 & & & & 7 & 6 & 2 & 31 & 4,68 & 9,09 \\
\hline $\mathrm{RC} 2 \mathrm{~F} 1$ & 25 & 9 & 2 & & & & & & & 36 & 1,36 & 0,35 \\
\hline
\end{tabular}

para o cruzamento entre BRS Firmeza e "Taim", que não expressou estas proporções nas gerações segregantes, o que indicou que estas cultivares possuem o mesmo gene de resistência a esta raça de
P. grisea. Estes resultados mostraram que a reação de resistência das cultivares de arroz irrigado "Taim" e BRS Firmeza para a raça IA-1abd é controlada por um único gene com dominância para a resistência. 
TABELA 2 - Teste de ajustamento do Qui-quadrado $\left(\chi^{2}\right)$, aplicado aos dados observados das reações de resistência nas gerações das plantas segregantes $\left(\mathrm{F}_{2}, \mathrm{RC}_{1} \mathrm{~F}_{1}\right.$ e $\left.\mathrm{RC}_{2} \mathrm{~F}_{1}\right)$

\begin{tabular}{|c|c|c|c|c|c|c|}
\hline \multirow[t]{2}{*}{ Cruzamentos e Gerações } & \multicolumn{2}{|c|}{$\begin{array}{c}\begin{array}{c}\text { Freqüência } \\
\text { observada }\end{array} \\
\end{array}$} & \multirow[t]{2}{*}{ Total } & \multirow[t]{2}{*}{ Freqüência esperada } & \multirow[t]{2}{*}{2} & \multirow[t]{2}{*}{ Probabilidade } \\
\hline & Resistente & Suscetível & & & & \\
\hline \multicolumn{7}{|l|}{ BRS 7 X Fanny } \\
\hline $\mathrm{F}_{2}$ & 125 & 40 & 165 & $3: 1$ & 0,051 & $0,90-0,80$ \\
\hline $\mathrm{RC}_{1} \mathrm{~F}_{1}$ & 21 & 24 & 45 & $1: 1$ & 0,200 & $0,70-0,50$ \\
\hline $\mathrm{RC}_{2} \mathrm{~F}_{1}$ & 49 & 0 & 49 & $1: 0$ & - & 100,00 \\
\hline \multicolumn{7}{|l|}{ Fanny X BRS 7} \\
\hline $\mathrm{F}_{2}$ & 117 & 39 & 156 & $3: 1$ & - & 100,00 \\
\hline $\mathrm{RC}_{1} \mathrm{~F}_{1}$ & 48 & 0 & 48 & $1: 0$ & - & 100,00 \\
\hline $\mathrm{RC}_{2} \mathrm{~F}_{1}$ & 25 & 24 & 49 & $1: 1$ & 0,020 & $0,95-0,90$ \\
\hline \multicolumn{7}{|c|}{ BRS 7 "Taim" X BRS Firmeza } \\
\hline $\mathrm{F}_{2}$ & 144 & 0 & 144 & $1: 0$ & - & 100,00 \\
\hline $\mathrm{RC}_{1} \mathrm{~F}_{1}$ & 43 & 0 & 43 & $1: 0$ & - & 100,00 \\
\hline $\mathrm{RC}_{2} \mathrm{~F}_{1}$ & 43 & 0 & 43 & $1: 0$ & - & 100,00 \\
\hline \multicolumn{7}{|c|}{ BRS Firmeza X BRS 7 "Taim” } \\
\hline $\mathrm{F}_{2}$ & 152 & 0 & 152 & $1: 0$ & - & 100,00 \\
\hline $\mathrm{RC}_{1} \mathrm{~F}_{1}$ & 38 & 0 & 38 & $1: 0$ & - & 100,00 \\
\hline $\mathrm{RC}_{2} \mathrm{~F}_{1}$ & 46 & 0 & 38 & $1: 0$ & - & 100,00 \\
\hline \multicolumn{7}{|l|}{ BRS Firmeza X Fanny } \\
\hline $\mathrm{F}_{2}$ & 105 & 37 & 142 & $3: 1$ & 0,085 & $0,8-0,70$ \\
\hline $\mathrm{RC}_{1} \mathrm{~F}_{1}$ & 31 & 0 & 31 & $1: 0$ & - & 100,00 \\
\hline $\mathrm{RC}_{2} \mathrm{~F}_{1}$ & 16 & 16 & 32 & $1: 1$ & - & 100,00 \\
\hline \multicolumn{7}{|l|}{ Fanny X BRS Firmeza } \\
\hline $\mathrm{F}_{2}$ & 109 & 36 & 145 & $3: 1$ & 0,023 & $0,95-0,90$ \\
\hline $\mathrm{RC}_{1} \mathrm{~F}_{1}$ & 23 & 23 & 46 & $1: 1$ & - & 100,00 \\
\hline $\mathrm{RC}_{2} \mathrm{~F}_{1}$ & 44 & 0 & 44 & $1: 0$ & - & 100,00 \\
\hline \multicolumn{7}{|c|}{ BRS Atalanta X BRS 7 "Taim" } \\
\hline $\mathrm{F}_{2}$ & 110 & 37 & 147 & $3: 1$ & 0,002 & $100,0-0,95$ \\
\hline $\mathrm{RC}_{1} \mathrm{~F}_{1}$ & 21 & 22 & 43 & $1: 1$ & 0,023 & $0,95-0,90$ \\
\hline $\mathrm{RC}_{2} \mathrm{~F}_{1}$ & 47 & 0 & 47 & $1: 0$ & - & 100,00 \\
\hline \multicolumn{7}{|c|}{ BRS 7 "Taim" X BRS Atalanta } \\
\hline $\mathrm{F}_{2}$ & 39 & 115 & 154 & $3: 1$ & 0,087 & $0,80-0,70$ \\
\hline $\mathrm{RC}_{1} \mathrm{~F}_{1}$ & 43 & 0 & 43 & $1: 0$ & - & 100,00 \\
\hline $\mathrm{RC}_{2} \mathrm{~F}_{1}$ & 23 & 23 & 46 & $1: 1$ & - & 100,00 \\
\hline \multicolumn{7}{|c|}{ BRS Atalanta X BRS Firmeza } \\
\hline $\mathrm{F}_{2}$ & 94 & 31 & 125 & $3: 1$ & 0,003 & $100-0,95$ \\
\hline $\mathrm{RC}_{1} \mathrm{~F}_{1}$ & 16 & 15 & 31 & $1: 1$ & 0,032 & $0,90-0,80$ \\
\hline $\mathrm{RC}_{2} \mathrm{~F}_{1}$ & 36 & 0 & 36 & $1: 0$ & - & 100,00 \\
\hline \multicolumn{7}{|c|}{ BRS Firmeza X BRS Atalanta } \\
\hline $\mathrm{F}_{2}$ & 106 & 38 & 144 & $3: 1$ & 0,148 & $0,70-0,80$ \\
\hline $\mathrm{RC}_{1} \mathrm{~F}_{1}$ & 43 & 0 & 43 & $1: 0$ & - & 100,00 \\
\hline $\mathrm{RC}_{2} \mathrm{~F}_{1}$ & 18 & 17 & 35 & $1: 1$ & 0,029 & $0,90-0,80$ \\
\hline
\end{tabular}

\section{REFERÊNCIAS BIBLIOGRÁFICAS}

BABUJEE, L. \& GNANAMANICKAM, S.S. Molecular tools for characterization of rice blast pathogen (Magnaporthe grisea) population and molecular marker-assisted breeding for disease resistance. Current Science 78:3:248-257, 2000.

BARMAN, S.R., GOWDA, M., VENU, R.C. \& CHATTOO, B.B. Identification of a major blast resistance gene in the rice cultivar te-tep. Plant Breeding 123:300-302. 2004.
BRYAN, G.T., WU, K.S., FARRALL, D., JIA, Y., HERSHEY, H.P., ACADAMS, S.A., FAULK, K.N., DONALDSON, G.K., TARCHINI, R. \& VALENT, B. A single amino acid difference distinguishes resistance and susceptible alleles of the rice blast resistance gene Pi-ta. The Plant Cell 12:2033-2045. 2000.

CIAT - Centro Internacional de Agricultura Tropical. Sistema de evaluación estándar para arroz. Cali, Colômbia. 1975.

INUKAI, T., NELSON, R.J., ZEIGLER, R.S., SARKARUNG, S., MACKILL, D.J., BONMAN, J.M., TAKAMURE, I. \& KINOSHITA, T. Allelism of blast resistance gene in near-isogenic 
lines of rice. Phytopathology 84:11:1278-1283. 1994.

INUKAI, T., MACKILL, D.J., BONMAN, J.M., SARKARUNG,S., EIGLAR, R., NELSON, R., TAKAMURE, I. \& KINOSHITA, T. Blast resistance gene Pi-2(t) and Pi-z may be allelic. Disponível em: http://www.shigen.nig.ac.jp/rice/rgn/vol9v9p90.html. Acesso em: 27/10/2005.

JIA, Y., WANG, Z., FJELLSTROM, R.G., MOLDENHAUER, A.K., AZAM, M., CORRELL, J., LEE, F.N., XIA, Y. \& RUTGER, J.N. Rice Pi-ta gene confers resistance to the major pathotypes of the rice blast fungus in the United States. Phytopathology 94:296301. 2004.

JEON, J.S., CHEN, D., YI, G.H., WANG, G.L. \& RONALD, P.C. Genetic and physical mapping of Pi5(t), a locus associated with broad spectrum resistance to rice blast. Molecular Genetics and Genomics 269:280-289. 2003.

McCOUCH, S.R., NELSON, R.J., TOHME, J. \& ZEIGLER, R.S.
Mapping of blast resistance genes in rice. In: Zeigler, R.S., Leong, S.A. \& Teng, P.S. (Eds.) Rice blast disease. Wallingford. CAB International. 1994. pp. 167-186.

PADMAVATHI, G., RAM, T., SATYANARAYANA, K. \& VISHRA, B. Identification of blast (Magnaporthe grisea) resistance gene in rice. Current Science 88:628-630. 2005.

STEEL, R.G.D. \& TORRIER, J.H. Principles and procedures of statistics. A biometrical approach. New York. 2nd Ed. McGrawHill. 1980.

TANAKA, Y. Estimativa de genes maiores para resistência a Pyricularia oryzae em cultivares de arroz irrigado no Brasil. Fitopatologia Brasileira 8:609. 1983. (Resumo)

ZHU, M., WANG, L. \& PAN, Q. Identification and characterization of a new blast resistance gene located on rice chromosome 1 through linkage and differential analyses. Phytopathology 94:515519. 2004. 